\title{
Single Voxel Spectroscopy Findings in Epileptic Children with Negative Conventional Magnetic Resonance Imaging of the Brain
}

H.A.El Ghaiaty,O.M.Abdel.Haie,M.M.Hosnyand A.S.Dabour

${ }^{1}$ Pediatrics Dept, Faculty of Medicine, Benha Univ, Benha, Egypt

${ }^{2}$ Radiology Dept, Faculty of Medicine, Benha Univ, Benha, Egypt

E-Mail:ah.dabour1986@gmail.com

\section{Abstract}

MRI plays a key role in the evaluation of pediatric patients with seizures and is considered important for the detection of epileptogenic lesions. However, MRS is not as widely used for the evaluation of children with seizures and is not included in the guidelines of the ILAE for the evaluation of infants and children with many types of epilepsy in 2009

Evaluate the Diagnostic and prognostic role of Magnetic Resonance Spectroscopy in the evaluation of nonlesional epilepsy in pediatric patients

Our study was a prospective controlled study. It had been held up on pediatric epileptic patients who were regularly following in the pediatric neurology clinic over one year from July 2017 to July 2018. It included two groups: the case group that included 50 epileptic children with normal conventional MRI brain study and the control group that included 20 non epileptic children.

there was statistical significant differences between patients with intractable seizures and those with nonintractable seizures regarding $\mathrm{NAA} / \mathrm{Cr}$ ratio in basal ganglia, white matter, Also there were statistical significant difference between patients with intractable seizures and those with non- intractable seizures regarding $\mathrm{NAA} / \mathrm{Cr}+\mathrm{Cho}$ ratio in basal ganglia. A ratio of $\mathrm{NAA} / \mathrm{Cr}$ in basal ganglia with best cut off value $\leq$ 1.5 could differentiate epileptic children who will respond to treatment from those with intractable seizures with sensitivity of $100 \%$ and specificity of $62 \%$. Also, a ratio of NAA/Cr in white matter with best cut off value $\leq 1.9$ $\mathrm{mg} / \mathrm{dl}$ could differentiate epileptic children who will respond to treatment from those with intractable seizures with sensitivity of $100 \%$ and specificity of $65 \%$.

MRS spectroscopy can be used as a prognostic tool to predict epileptic children who will develop intractable epilepsy

\section{Introduction}

An seizure may be characterized Likewise "a transient event about indications or manifestations because of abnormal over the top alternately synchronous neuronal movement in the mind [1]. Accepted $\mathrm{mr}$ imaging might faultlessly confine the seizure onset region, for example, Toward distinguishing one-sided hippocampal decay alternately malformations of cortical development, however, $\mathrm{mr}$ imaging might frequently all the be negative or vague [eg, reciprocal involvement] and, over exactly cases, lesions seen In mr imaging might not match those concentrate about seizure onset recognized Toward method for obtrusive electroencephalographic estimations. [2].

However, mrs may be not Likewise generally utilized for the assessment for Youngsters for seizures Furthermore will be not incorporated in the rules of the ILAE for the assessment for babies and know youngsters for a lot of people sorts about epilepsy On 2009 What's more clinched alongside its proposals to those management for childish seizures once more to 2015 [3].

Attractive reverberation [MR] spectroscopy may be an explanatory strategy utilized within science that empowers those ID number Furthermore quantification for metabolites in specimens. It contrasts starting with traditional $\mathrm{mr}$ imaging in that spectra furnish physiologic Also compound data As opposed to life structures [4].

Concerning illustration there is overpowering proof that metabolic brokenness will be normal over human epilepsy, and habitually particular sufficient will identify those seizure onset zone for a significant number patients [5]. $\mathrm{Mr}$ spectroscopy might offer possibility Previously, presurgical choice making clinched alongside patients for no abnormality In customary $\mathrm{mr}$ imaging alternately clinched alongside the individuals with a reciprocal epileptogenic zone with respect to electroencephalographic recordings. [6]. $\mathrm{Mr}$ spectroscopy need demonstrated clinically advantageous in suspicion of Hosting metabolic issue owing of the exceptional capability should noninvasively identify the metabolic abandon in vivo. To example, the vicinity from claiming pyruvate [plus lac and/ or alanine] What's more succinate need aid initial indicators about pyruvate and succinate dehydrogenase intricate deficiencies, separately.

In this study, our fundamental purposeful might have been on assess assess those symptomatic What's more prognostic part of attractive reverberation spectroscopy in the assessment of non-lesional epilepsy over pediatric patients. 


\section{Subjects\& methods}

Our study was a prospective controlled study. It had been held up on pediatric epileptic patients who were regularly following in the pediatric neurology clinic of Benha university hospital over one year from July 2017 to July 2018. A written informed consent was taken from the parents. 70 patients were included in our prospective study. There were 41 males and 29 females. We divided them into 2 groups; case group [50 patients] and control group [20 patients].

\subsection{Inclusion criteria of patients}

- Children from 1 to 18 years old from both genders.

- Children diagnosed with epilepsy according to the definition of epilepsy by the international league against epilepsy 2014

- Patients with unremarkable conventional MR study

- At least 1 week had been elapsed since last attack of seizure to avoid effect of transient metabolic changes following seizures.

\subsection{Exclusion criteria}

- Contraindications to MRI [such as pacemakers, cochlear implants].

- Epileptic children who have lesions in conventional MRI imaging.

\subsection{Methods}

All children were subjected to the following:

- Full history taking including perinatal history, developmental history, history of consanguinity, family history of epilepsy or febrile convulsion, semiology of the seizures, the age of onset, type of antiepileptic drugs, response to treatment, seizure frequency, compliance to treatment. Seizure type was determined according to the revised operational classification done by The International League against Epilepsy [ILAE] in 2017

- Physical examination [general \&local] including full neurological examination.

- Inter-ictal EEG monitoring using scalp electrodes applied according to 10-20 system for 20minuteswith hyperventilation for 3 minutes and photic stimulation as a provocative maneuvers.

- Magnetic Resonance Imaging: MRI imaging was held up using 1.5T Siemens [MAGNETOM Aera] machine [48 channels] [head/neck 20 channels coil],

- Single Voxel Spectroscopy [SVS]: voxel was placed at the left Centrum semi ovale region, the left basal ganglia and the midline parieto occipital regions. Examination was done using short echo time TE [30 msec] and long echo time TE [135 msec] with voxel size 2-5 $\mathrm{ml}$.The integral values of various metabolite peaks were evaluated in every voxel, using integrals of each peak as a measure of its intensity. Three resonances of the important metabolites were identified: NAA at $2.02 \mathrm{ppm}, \mathrm{Cr}$ at $3.02 \mathrm{ppm}$, and Cho at $3.22 \mathrm{ppm}$. The NAA/Cho ratio, the NAA/Cr ratio and the $\mathrm{NAA} / \mathrm{Cr}+\mathrm{Cho}$ ratios were calculated in the three different sites [the white matter, basal ganglia and grey matter].

\subsection{Statistical methods}

Data management and statistical analysis were done using SPSS vs.25. [IBM, Armonk, New York, United states].Numerical data was summarized as means and standard deviations. Categorical data was summarized as numbers and percentages. Comparisons between two groups were done using Mann Whitney $\mathrm{U}$ test for numerical data. Categorical data was compared using Chi-square test or Fisher's exact test if appropriate. Correlation analysis between different metabolites was done using Pearson's correlation. $\mathrm{r} \mathrm{r}$ is the correlation coefficient. It ranges from -1 to +1 . -1 indicates strong negative correlation, +1 indicates strong positive correlation while 0 indicates no correlation. All $\mathrm{P}$ values were two sided. $\mathrm{P}$ values less than 0.05 were considered significant.

\section{Results}

70 patients were included in our prospective study. There were 41 males and 29 females. We divided them into 2 groups; case group [50 patients] and control group [20 patients].There was no significant statistical difference between case and control groups regarding sex and family history of epilepsy as shown in table [1].

Table [1] General characteristics of Case and control groups.

\begin{tabular}{|c|c|c|c|c|}
\hline & & $\begin{array}{c}\text { Cases } \\
{[\mathrm{n}=\mathbf{5 0}]}\end{array}$ & $\begin{array}{l}\text { Controls } \\
{[n=20]}\end{array}$ & $P$ value \\
\hline Age [years] & Mean \pm SD & $5 \pm 3$ & $6 \pm 4$ & 0.937 \\
\hline \multirow[t]{2}{*}{ Gender } & Males & $30[60.0]$ & $11[55.0]$ & 0.701 \\
\hline & Females $\mathrm{n}[\%]$ & $20[40.0]$ & $9[45.0]$ & \\
\hline Family history of epilepsy & Positive $\mathrm{n}[\%]$ & $2[4.0]$ & $0[0.0]$ & 1.0 \\
\hline
\end{tabular}


According to the type of seizures and seizures control, the case group was subdivided as described in Table [2].

Table [2] Type and nature of seizures in cases

$$
\text { 2]. }
$$

\begin{tabular}{lll}
\hline \multirow{2}{*}{ Type of seizures } & & $\mathbf{n}[\mathbf{\%}]$ \\
\cline { 2 - 3 } & Generalized clonic & $44[88.0]$ \\
\hline \multirow{3}{*}{ Seizures control } & Focal & $2[4.0]$ \\
& Focal with impaired awareness & $2[4.0]$ \\
& Myoclonic & $2[4.0]$ \\
& Intractable & $8[16.0]$ \\
\hline
\end{tabular}

There were no statistical significant differences between the case and control groups regarding the calculated NAA/Cho ratio in basal ganglion, white matter and cortical grey matter as shown in Table [3].

Table [3] NAA/Cho in basal ganglia, white matter and cortical grey matter in case and control groups

\begin{tabular}{llll}
\hline & $\begin{array}{l}\text { Cases }[\mathbf{n}=\mathbf{5 0}] \\
\text { Mean } \mathbf{\pm S D}\end{array}$ & $\begin{array}{l}\text { Controls }[\mathbf{n}=\mathbf{2 0}] \\
\text { Mean } \mathbf{\mathbf { S D }}\end{array}$ & P value \\
\hline In basal ganglia & $2.4 \pm 0.57$ & $2.24 \pm 0.49$ & 0.268 \\
In white matter & $1.9 \pm 0.36$ & $1.86 \pm 0.25$ & 0.629 \\
In grey matter & $3.1 \pm 1.12$ & $2.79 \pm 1.23$ & 0.467 \\
\hline
\end{tabular}

Our results showed no significant statistical differences between cases and controls groups regarding the calculated $\mathrm{NAA} / \mathrm{Cr}$ ratio in basal ganglion, white matter and cortical grey matter as shown in Table [4].

Table [4] NAA/Cr in basal ganglia, white matter and cortical grey matter in case and control groups

\begin{tabular}{llll}
\hline & $\begin{array}{l}\text { Cases }[\mathbf{n}=\mathbf{5 0}] \\
\text { Mean } \pm \text { SD }\end{array}$ & $\begin{array}{l}\text { Controls }[\mathbf{n}=\mathbf{2 0}] \\
\text { Mean } \pm \text { SD }\end{array}$ & P value \\
\hline In basal ganglion & $1.63 \pm 0.31$ & $1.69 \pm 0.23$ & 0.281 \\
In white matter & $1.86 \pm 0.33$ & $1.69 \pm 0.39$ & 0.13 \\
In grey matter & $1.84 \pm 0.29$ & $1.85 \pm 0.55$ & 0.799 \\
\hline
\end{tabular}

There were no statistical significant differences between the cases with intractable seizures and those with non-intractable seizures regarding the calculated NAA/Cho ratio in basal ganglion, white matter and cortical grey matter as shown in Table [5].

Table [5] NAA/Cho in basal ganglia, white matter and grey matter according to seizures control

\begin{tabular}{llll}
\hline & Intractable $[\mathbf{n}=\mathbf{8}]$ & Non-intractable $[\mathbf{n}=\mathbf{4 2}]$ & \\
\hline & Mean $\mathbf{\pm S D}$ & Mean \pm SD & P value \\
\hline In basal ganglia & $2.24 \pm 0.72$ & $2.43 \pm 0.55$ & 0.687 \\
In white matter & $2.02 \pm 0.34$ & $1.88 \pm 0.37$ & 0.254 \\
In grey matter & $3.02 \pm 1.1$ & $3.12 \pm 1.14$ & 0.482
\end{tabular}

$\mathrm{We}$ found statistical significant differences $\quad[\mathrm{P}$ value $=0.005$ and 0.043 respectively $]$ and between cases with intractable seizures and those borderline significant with $\mathrm{p}$ value 0.06 in cortical with non-intractable seizures regarding the grey matter as shown in Table [6]. calculated NAA/Cr ratio in basal ganglion \& white

Table [6] NAA/Cr in basal ganglia, white matter and grey matter according to seizures control

\begin{tabular}{|c|c|c|c|}
\hline & Intractable [n = 8] & Non-intractable $[n=42]$ & \\
\hline & Mean \pm SD & Mean \pm SD & P value \\
\hline In basal ganglion & $1.39 \pm 0.12$ & $1.67 \pm 0.31$ & $0.005 *$ \\
\hline In white matter & $1.69 \pm 0.21$ & $1.89 \pm 0.34$ & $0.043 *$ \\
\hline In grey matter & $1.67 \pm 0.18$ & $1.87 \pm 0.29$ & $0.06 * *$ \\
\hline
\end{tabular}


Our work showed statistical significant differences between patients with generalized seizures and those with other seizure semiology regarding the calculated NAA/Cho ratio in basal ganglion and cortical grey matter, but no statistical significant differences noted in the white matter as shown in Table [7].

Table [7] NAA/Cho in basal ganglia, white matter and cortical grey matter according to seizures type

\begin{tabular}{llll}
\hline & Generalized $[\mathbf{n}=\mathbf{4 4}]$ & Others $[\mathbf{n}=\mathbf{6}]$ & \\
\hline & Mean \pm SD & Mean \pm SD & P value \\
\hline In basal ganglion & $2.33 \pm 0.56$ & $2.88 \pm 0.5$ & $0.012^{*}$ \\
In white matter & $1.91 \pm 0.37$ & $1.79 \pm 0.35$ & 0.812 \\
In grey matter & $2.81 \pm 0.79$ & $4.96 \pm 1.16$ & $<0.001^{*}$ \\
\hline
\end{tabular}

Our work revealed statistical significant differences between patients with generalized clonic seizures and those with other seizure semiology regarding $\mathrm{NAA} / \mathrm{Cr}+\mathrm{Cho}$ ratio in cortical grey matter $[\mathrm{P}$ value $=0.016]$ with no significant difference noted in the white matter and basal ganglia as shown in Table [8].

Table [8] NAA/Cr+Cho in basal ganglia, white matter and grey matter according to seizures type

\begin{tabular}{llll}
\hline & Generalized $[\mathbf{n}=\mathbf{4 4}]$ & Others $[\mathbf{n}=\mathbf{6}]$ & \\
\hline & Mean \pm SD & Mean \pm SD & P value \\
\hline In basal ganglia & $0.96 \pm 0.15$ & $1.09 \pm 0.22$ & 0.125 \\
In white matter & $0.975 \pm 0.19$ & $0.903 \pm 0.083$ & 0.108 \\
In grey matter & $1.11 \pm 0.18$ & $1.43 \pm 0.26$ & $0.016^{*}$ \\
\hline
\end{tabular}

ROC curve was constructed for NAA/Cr ratio in basal ganglia and gave cut off value $\leq 1.5$ for epileptic patients who could respond to medical treatment from those with intractable seizures, with combined sensitivity and specificity $100 \%$ and $62 \%$ respectively and area under the curve of 0.81 ; $[\mathrm{P}<0.05]$ as shown in Fig [1].
Also, ROC curve was constructed for the $\mathrm{NAA} / \mathrm{Cr}$ ratio in white matter \& found cut off value $\leq 1.9$ could differentiate epileptic children who will respond to treatment from those with intractable seizures area under the curve, with best combined sensitivity and specificity of $100 \%$ and $65 \%$ respectively. $\mathrm{AUC}=0.758 ;[\mathrm{P}<0.05]$ as shown in Fig [2].

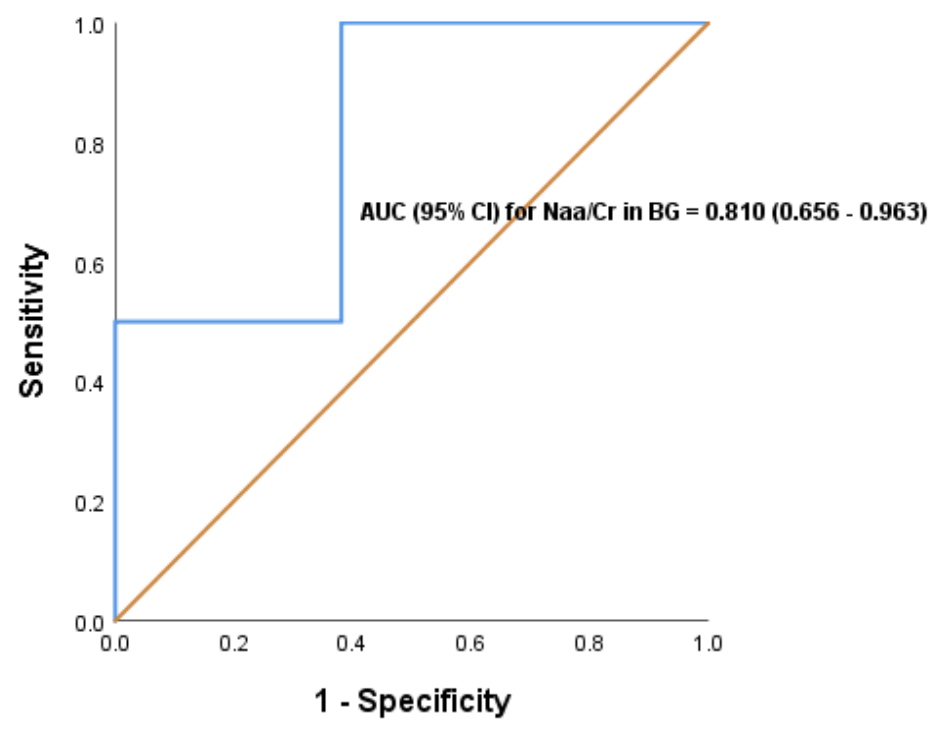

Fig [1] ROC analysis for NAA/Cr in BG for prediction of intractable seizures 


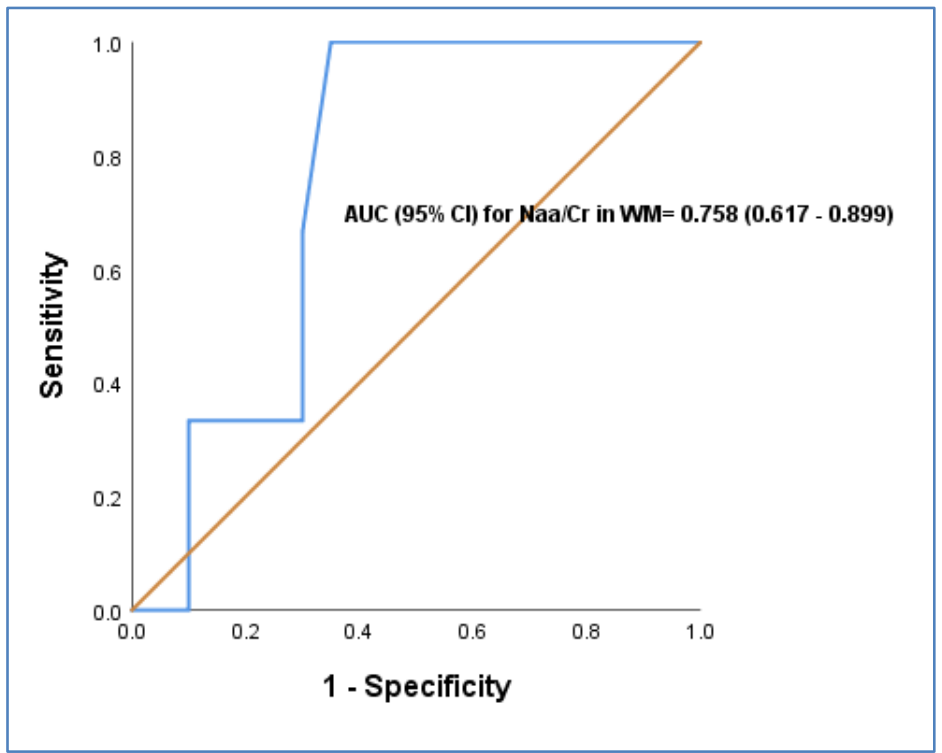

Fig [2] ROC analysis for NAA/Cr in WM for prediction of intractable seizures

\section{Discussion}

Epileptic seizures affect 1-2 \% of the Populace What's more $4 \%$ of know youngsters. Youth epilepsy need a predominance from claiming pretty nearly $0.5-0.8 \%$ and comprises a heterogeneous assembly about disorders, including an assortment of epilepsy syndromes that run in seriousness starting with Favorable on progressive and calamitous [7].

$\mathrm{H} \mathrm{mr}$ spectroscopy is a guaranteeing strategy that gives in vivo biochemical majority of the data looking into an assortment about cerebrum mixes. Those objective from claiming this prospective contemplate might have been will focus how frequently mrs will give acceptable extra majority of the data to traditional mri to epileptic Youngsters who don't have lese greatness to routine mri imaging What's more assess if mrs might make utilized Likewise a standout amongst the predictors of unmanageability for epileptic seizures Previously, know youngsters age class.

In the present study, those situation one assembly incorporated 50 epileptic patients, 30 guys [60\%] Also 20 females [40\%] with imply agdistis $5 \pm 3$ a considerable length of time. Those control gathering incorporated 20 patients, 11 guys [55\%] Furthermore 9 females [45\%] with imply agdistis $6 \pm 4$ quite some time. To the vast majority later investigations that report card gender, like study led Eventually Tom's perusing Hawley et al during 2015 clinched alongside country kansas contemplate one assembly gender-specific frequency done know youngsters may be higher over males, in spite of the fact that rarely fundamentally In this way [8].

Those case aggregation included 8 patients [16\%] who required immovable epilepsy requiring more than 2 pills for control of seizures
Furthermore 42 patients [84\%] who need aid controlled for medications. This try with the dutch consider Eventually Tom's perusing human experience et al directed Similarly as 5-year catch up investigation of epilepsy in adolescence who found that $6-14 \%$ for Youngsters produced immovable epilepsy [9].

Those A large portion incessant kind from claiming seizures might have been summed up tonic stress clonic seizures $88 \%$ emulated Eventually Tom's perusing central seizures with mindfulness which spoke to $4 \%$, central seizures with impeded consciousness 4\% What's more myoclonic seizures which also spoke to $4 \%$. This may be in understanding with Wafaa et al, who led An investigation to figure out those pervasiveness Furthermore clinical example about epilepsy "around know youngsters Furthermore youths over upper egypt. [10] this study showed that summed up seizures were that's only the tip of the iceberg incessant to adolescence and youth At without statistically noteworthy distinction. For our consider we utilized single voxel spectroscopy strategy utilizing short te deum $[30 \mathrm{msec}]$ and in length te deum [135 msec] for voxel span 2-5ml. Those voxel might have been put at those left centrum semi ovale area speaking to white matter, those cleared out basal ganglia and the midline parieto -occipital locales speaking to those ash is concerned.

On our contemplate, on analyzings the mrs discoveries of both the the event Also control Assemblies, there might have been no measurable critical contrasts viewing those taking after metabolite ratios, the NAA/Cho proportion ,the $\mathrm{NAA} / \mathrm{Cr}$ proportion and the $\mathrm{NAA} / \mathrm{Cr}+\mathrm{Cho}$ proportion in the white is concerned, basal ganglia What's more ash matter destinations. This will be in 
contradiction with Azab et. Al that think about the $\mathrm{NAA} / \mathrm{Cr}$ proportion the middle of 40 patients diagnosed Similarly as Hosting transient flap epilepsy Also 20 solid know youngsters Concerning illustration the control assembly. They discovered critical Contrast the middle of the patients and the control bunches with An diminished level of the NAA/Cr proportion in the patients bunches. [11]. This camwood be demonstrated as our study might have been led on non lesional epilepsy without ID number of the epileptogenic concentrate same time alternate investigations were led over lesional epilepsy in which those epileptogenic center might have been presumed through routine mri for alternately without the help about eeg and/ or fluoro deoxyglucose-positron emanation tomorrow [FDG-PET].

For thinking about metabolite proportions Previously, both bunches for immovable Furthermore non-intractable epilepsy there were measurable noteworthy Contrast the middle of the two gatherings in regards to. 1- NAA/Cr proportion Previously, basal ganglion, white is concerned What's more ash matter with p values under 0.05 .

2- NAA/Cr+Cho proportion On basal ganglion with $\mathrm{p}$ worth 0.073 .

This is concurred upon for Aziz et al. Who led contemplate will assess the part of attractive reverberation spectroscopy [MRS] to non lesional worldly flap epilepsy. They discovered that lessened NAA/Cho + cr proportion considers lateralization of the epileptogenic keep tabs over analyzings both fleeting lobes [12].

For our consider there were Factual noteworthy contrasts the middle of patients for summed up clonic seizures What's more the individuals for other seizure semiology viewing.

1- NAA/Cho proportion in basal ganglia, Also ash is concerned.

2- NAA/Cr proportion On white matter.

3- NAA/Cr+Cho proportion clinched alongside ash is concerned.

This will be in understanding for Kasper et al who utilized multi voxel attractive reverberation spectroscopy with contemplate the degree from claiming nearby metabolic alterations for patients with idiopathic infection summed up epilepsy. They rely on upon those outright values of the metabolites instead of proportions. They found critical [ $<<0.05]$ diminishing for tNAA in the ash matter, thalamus What's more basal ganglia. [13]. This could make demonstrated Toward those following:.

1- summed up epilepsies include proliferation of the epileptic release through epileptic networks to both cerebral hemispheres.

2- those cerebrum may be touchy on transforms inside certain networks, with a sequential engagement for whatever remains of those mind because of interconnectedness networks, which exhibit the idea of what may be called epilepsy networks. [14].

3- inclusion about basal ganglia may be Possibly Likewise An proliferation pathway or as a remote inhibitory control circuit, those basal ganglia would included to controlling those cortical excitability, also to spread, regulation Also hold on in of seizures. The input from those basal ganglia may be principally inhibitory, while those engine cortex sends excitatory yield. Basal ganglia to cortex horrendous circle for excitatory terminating about cortical phones [e. G. Coming about because of cortical microdysgenesis] and impeded inhibitory reaction of the basal ganglia could make those underlying reason for seizure. [13].

\section{Conclusion}

In light of those past observations, we might hypothesize that mrs contributes of the management, diagnosis, and prognosis about pediatric patients for seizures.

\section{Recommendation}

Our study might have been done at An attractive field quality about $1.5 \mathrm{t}$. An higher-field quality of $3 \mathrm{t}$ alternately a greater amount might need yielded An exceptional spatial determination What's more secondary indicator on commotion proportion.

Also, mrs could be utilized within the assessment for non-lesional pediatric epilepsy to those finding of neurometabolic issue eg. Creatine insufficiency disorders, mitochondrial issue.

\section{References}

[1] R.Fisher, J.Cross, J.French, N.Higurashi, E.Hirsch, F.Jansen, Operational classification of seizure types by the International League Against Epilepsy: Position Paper of the ILAE Commission for Classification and Terminology. Epilepsia ,vol.58(4),pp.522-530, 2017.

[2] G, J.Alger, P.Barker, R.Bartha, A.Bizzi, C.Boesch,Clinical Proton MR Spectroscopy in Central Nervous System Disorders. Radiology,vol.270(3),pp.658-679, 2014.

[3] S.Rincon, M.Blitstein, P.Caruso, González R, Thibert R, Rtaai E., The Use of Magnetic Resonance Spectroscopy in the Evaluation of Pediatric Patients With Seizures. Pediatric Neurology, Vol.58,pp.57-66,2016.

[4] Bertholdo D, Watcharakorn A, M.Castillo, Brain Proton Magnetic Resonance Spectroscopy. Neuroimaging Clinics of North America, Vol.23 (3),pp.359-380,2013.

[5] J.Pan, R.Duckrow, J.Gerrard, C.Ong, L.Hirsch, S.Resor, 7T MR spectroscopic imaging in the 
localization of surgical epilepsy. Epilepsia,vol.54(9),pp.1668-1678, 2013.

[6] T.Hammen, R.Kuzniecky, Magnetic resonance spectroscopy in epilepsy. Handbook of Clinical Neurology, Vol.59,pp.399-408,2012.

[7] J.Cross, G.Kluger, L.Lagae , Advancing the management of childhood epilepsies. European Journal of Paediatric Neurology,Vol.17(4),pp.334-347,2013.

[8] S.Hawley, E.Ablah, D.Hesdorffer, J.Pellock, D.Lindeman, A.Paschal, Prevalence of pediatric epilepsy in low-income rural Midwestern counties. Epilepsy \& Behavior,vol.53,pp.190$196,2015$.

[9] W.Arts, O.Brouwer, A.Peters, H.Stroink, E.Peeters, P.Schmitz,Course and prognosis of childhood epilepsy: 5-year follow-up of the Dutch study of epilepsy in childhood. Brain.,Vol.127(8),pp.1774-1784, 2004.

[10] W.Farghaly, M.Abd Elhamed, E.Hassan, W.Soliman, M.Yhia, N.Hamdy: Prevalence of childhood and adolescence epilepsy in Upper Egypt [desert areas]. The Egyptian Journal of Neurology, Psychiatry and Neurosurgery,vol.54(1),pp.669-784,2018.

[11] S.Azab, L.Sherief, S.Saleh, M.Elshafeiy, A.Siam, W.Elsaeed, Childhood temporal lobe epilepsy: correlation between electroencephalography and magnetic resonance spectroscopy: a case-control study. Italian Journal of Pediatrics, Vol.41(1), pp. 149-152,2015.

[12] A.Aun, A.Mostafa, A.Aboul Fotouh, K.Karam, A.Salem, Role of magnetic resonance spectroscopy [MRS] in nonlesional temporal lobe epilepsy. The Egyptian Journal of Radiology and Nuclear Medicine,vol.47(1),pp.217-231,2016.

[13] M.Doelken, A.Mennecke, A.Stadlbauer, L .Kecskeméti, B.Kasper, T.Struffert, Multi-voxel magnetic resonance spectroscopy at $3 \mathrm{~T}$ in patients with idiopathic generalised epilepsy. Seizure,vol.19(8),pp.485-492, 2010.

[14] T.Veenendaal, W.Backes, D.Tse, T. Scheenen, D.Klomp, P.Hofman , High field imaging of large-scale neurotransmitter networks: Proof of concept and initial application to epilepsy. NeuroImage: Clinical,vol.19,pp.47-55,2018. 